\title{
Performance of Different Orthodontic Brackets after Exposure to Dietary Components: An in Vitro Pilot Study
}

\author{
Anthony Fusco' ${ }^{1}$, Syed Ahmed ${ }^{1}$, Jared Link1, Tanya Al-Talib², Neamat Hassan Abubakr ${ }^{3 *}$ \\ ${ }^{1}$ DMD School of Dental Medicine, University of Nevada, Las Vegas, NV, USA \\ ${ }^{2}$ Department of Clinical Sciences, School of Dental Medicine, University of Nevada, Las Vegas, NV, USA \\ ${ }^{3}$ Department of Biomedical Sciences, School of Dental Medicine, University of Nevada, Las Vegas, NV, USA \\ Email: *neamat.hassan@unlv.edu
}

How to cite this paper: Fusco, A., Ahmed, S., Link, J., Al-Talib, T. and Abubakr, N.H. (2021) Performance of Different Orthodontic Brackets after Exposure to Dietary Components: An in Vitro Pilot Study. Open Journal of Stomatology, 11, 341-348. https://doi.org/10.4236/ojst.2021.119030

Received: August 3, 2021

Accepted: September 10, 2021

Published: September 13, 2021

Copyright $\odot 2021$ by author(s) and Scientific Research Publishing Inc. This work is licensed under the Creative Commons Attribution-NonCommercial International License (CC BY-NC 4.0). http://creativecommons.org/licenses/by-nc/4.0/

\begin{abstract}
Introduction: The aim of this study was to determine whether there was a significant difference in shear bond strength between metal and ceramic brackets when exposed to acidic dietary components (beverages) and to observe the chromogenic potential of each in vitro. Methods: Metal and clear orthodontic brackets were placed on extracted maxillary second premolars and exposed to select beverages three times daily for four weeks. Shade was taken using a colorimeter device at seven intervals and the shear bond strength of each bracket was recorded. Results: There was a variable change in tooth shade with respect to the various beverages in which they were submerged. Coffee and Dr. Pepper had the most pronounced change, whereas Red Bull and water produced little to none, respectively. Compared to controls, brackets submerged in coffee had the greatest reduction in shear bond strength, followed by Dr. Pepper, then Red Bull. Overall, clear brackets showed higher shear bond strength than metal brackets. Conclusion: Acidic dietary components have a negative effect on the shear bond strength of orthodontic brackets, and more pigmented beverages have a higher chromogenic staining potential.
\end{abstract}

\section{Keywords}

Bracket, Shear Bond Strength, Orthodontics, Tooth Shade

\section{Introduction}

In orthodontic treatment, esthetic concerns are as important as functional demands [1]. Fixed orthodontic appliances have been found to cause tooth color 
changes, and high consumption of acidic beverages may result in increased enamel and dentin susceptibility to exogenous acids originating from those beverages, such as energy drinks [2] [3]. An increase in the consumption of low $\mathrm{pH}$ soft drinks, especially among teenagers, has been observed [4]. Frequent consumption of carbonated acidic drinks provides a regular supply of corrosive agents in addition to other contributors of acid to the oral cavity, such as fluoride-containing products like toothpaste and mouthwash. Clinically, this is problematic as an acidic environment increases the corrosion susceptibility of certain metals, especially titanium [5]. Numerous tests have been used to investigate the in vivo and in vitro color stability of dental materials for artificial aging [6] [7] [8]. The effect of dietary components on the seal of orthodontic adhesives demonstrated areas of adhesive loss from the enamel after exposure to the low pH dietary components or food-simulating media [9] [10]. It has been shown that acidic soft drinks have a negative effect on bracket retention against shearing forces [11].

The present in vitro pilot study aimed to evaluate the performance of two types of orthodontic brackets (metal and ceramic) with respect to shear bond strength (SBS) when exposed to various dietary components in addition to the chromogenic potential of common acidic, pigmented beverages.

\section{Methods}

Metal and clear orthodontic brackets (3 M Unitek) were bonded to 24 extracted maxillary second premolars (a set of 12 for each type of bracket, $n=12$ ) using Greenglo cement (Ormco Corp.). Inclusion criteria consisted of teeth with wholly sound tooth structure without evidence of fracture or enamel defects. Three dietary solutions were selected by an informal survey of dental students that chose their favorite soft drink, Red Bull variety, and Keurig K-cup coffee brand/roast. The most popular choices were Dr. Pepper, Red Bull classic, and Starbucks medium roast K-cups with tap water used as a control. The $\mathrm{pH}$ of each solution was as follows: Dr. Pepper $(2.88 \pm 0.04)$, Red Bull $(3.43 \pm 0.01)$, Starbucks medium roast (5.11 \pm 0.05 ), and tap water (average of 7.9) [12] [13]. We chose to use tap water rather than artificial saliva due to the variability of formulas by brand and the introduction of an additional set of confounding variables that would further complicate data interpretation [14]. The bonded teeth were ultimately divided into eight groups: Three active groups and one control for both metal and clear brackets $(n=3)$. To avoid any bias and ensure randomization and blinding, specimens were number-coded and randomly selected for the tests. Teeth were immersed in each dietary solution and water for $15 \mathrm{mi}$ nutes three times daily at different intervals to simulate an in vivo environment and were stored in regular water at room temperature $\left(23^{\circ} \mathrm{C}\right)$ between immersions. For each immersion, a new bottle was opened and the coffee samples were freshly brewed, keeping in line with standard preparation for consumption.

For tooth shade, an electronic colorimeter (VITA Easyshade V) was used. Re- 
cordings were taken three times at three locations: occlusally at the center of the central groove, and interproximally at the center of the mesial and distal surfaces. Each recorded reading in Table 1 was the average of nine readings taken for each tooth immediately after immersion. In this case, because shade is not easily quantifiable, the term "average" refers to the reading that was reproduced the most frequently from the nine instances. Readings of the classic VITA shade and 3D VITA shade were recorded immediate post-bonding, after 24 hours, 72

Table 1. Average readings of the classic VITA shade and 3D VITA.

\begin{tabular}{|c|c|c|c|c|c|c|c|}
\hline $\begin{array}{c}\text { Teeth with } \\
\text { Metallic Bracket }\end{array}$ & $\begin{array}{c}\text { Post } \\
\text { placement }\end{array}$ & 24 Hours & 72 Hours & 1 Week & 2 Weeks & 3 Weeks & 4 Weeks \\
\hline WM1 & $5 \mathrm{~m} 1, \mathrm{C} 4$ & $5 \mathrm{~m} 1, \mathrm{C} 4$ & $5 \mathrm{~m} 1, \mathrm{C} 4$ & $5 \mathrm{~m} 1, \mathrm{C} 4$ & $5 \mathrm{~m} 1, \mathrm{C} 4$ & $5 \mathrm{~m} 1, \mathrm{C} 4$ & $5 \mathrm{~m} 1, \mathrm{C} 4$ \\
\hline WM2 & $4 \mathrm{M} 3, \mathrm{~A} 4$ & $4 \mathrm{M} 3, \mathrm{~A} 4$ & $4 \mathrm{M} 3, \mathrm{~A} 4$ & $4 \mathrm{M} 3, \mathrm{~A} 4$ & $4 \mathrm{M} 3, \mathrm{~A} 4$ & $4 \mathrm{M} 3, \mathrm{~A} 4$ & $4 \mathrm{M} 3, \mathrm{~A} 4$ \\
\hline WM3 & $3 \mathrm{M} 3, \mathrm{~A} 3.5$ & $3 \mathrm{M} 3, \mathrm{~A} 3.5$ & $3 \mathrm{M} 3, \mathrm{~A} 3.5$ & $3 \mathrm{M} 3, \mathrm{~A} 3.5$ & $3 \mathrm{M} 3, \mathrm{~A} 3.5$ & 4L2.5, A3.5 & $4 \mathrm{~L} 2.5, \mathrm{~A} 4$ \\
\hline DrM1 & $5 \mathrm{~m} 2, \mathrm{C} 4$ & $5 \mathrm{~m} 2, \mathrm{C} 4$ & $5 \mathrm{~m} 2, \mathrm{C} 4$ & $5 \mathrm{~m} 3, \mathrm{C} 4$ & $5 \mathrm{~m} 3, \mathrm{C} 4$ & $5 \mathrm{~m} 3, \mathrm{C} 4$ & $5 \mathrm{~m} 3, \mathrm{C} 4$ \\
\hline DrM2 & $5 \mathrm{~m} 1, \mathrm{C} 4$ & $5 \mathrm{~m} 1, \mathrm{C} 4$ & $5 \mathrm{~m} 1, \mathrm{C} 4$ & $5 \mathrm{~m} 2, \mathrm{C} 4$ & $5 \mathrm{~m} 2, \mathrm{C} 4$ & $5 \mathrm{~m} 3, \mathrm{C} 4$ & $5 \mathrm{~m} 3, \mathrm{C} 4$ \\
\hline DrM3 & $4 \mathrm{~m} 3, \mathrm{C} 4$ & $5 \mathrm{M} 2, \mathrm{C} 4$ & $5 \mathrm{M} 2, \mathrm{C} 4$ & $5 \mathrm{~m} 3, \mathrm{C} 4$ & $5 \mathrm{~m} 3, \mathrm{C} 4$ & $5 \mathrm{~m} 3, \mathrm{C} 4$ & $5 \mathrm{~m} 3, \mathrm{C} 4$ \\
\hline CM1 & $2 \mathrm{~m} 3, \mathrm{~B} 3$ & $4 \mathrm{r} 2.5, \mathrm{~A} 4$ & $4 \mathrm{M} 3, \mathrm{C} 4$ & $5 \mathrm{M} 3, \mathrm{C} 4$ & $5 \mathrm{M} 3, \mathrm{C} 4$ & $5 \mathrm{M} 3, \mathrm{C} 4$ & $5 \mathrm{M} 3, \mathrm{C} 4$ \\
\hline $\mathrm{CM} 2$ & $5 \mathrm{~m} 1, \mathrm{C} 4$ & $5 \mathrm{~m} 2, \mathrm{C} 4$ & $5 \mathrm{M} 3, \mathrm{C} 4$ & $5 \mathrm{M} 3, \mathrm{C} 4$ & $5 \mathrm{M} 3, \mathrm{C} 4$ & $5 \mathrm{M} 3, \mathrm{C} 4$ & $5 \mathrm{M} 3, \mathrm{C} 4$ \\
\hline CM3 & $4 \mathrm{~m} 3, \mathrm{~A} 4$ & $5 \mathrm{~m} 1, \mathrm{C} 4$ & $5 \mathrm{M} 2, \mathrm{C} 4$ & $5 \mathrm{M} 2, \mathrm{C} 4$ & $5 \mathrm{M} 2, \mathrm{C} 4$ & $5 \mathrm{M} 2, \mathrm{C} 4$ & $5 \mathrm{M} 2, \mathrm{C} 4$ \\
\hline EM1 & $4 \mathrm{~L} 2.5, \mathrm{~A} 4$ & $4 \mathrm{~L} 2.5, \mathrm{~A} 4$ & $4 \mathrm{M} 2, \mathrm{~A} 4$ & $4 \mathrm{M} 3, \mathrm{~A} 4$ & $4 \mathrm{M} 3, \mathrm{~A} 4$ & $4 \mathrm{M} 3, \mathrm{~A} 4$ & $4 \mathrm{M} 3, \mathrm{~A} 4$ \\
\hline EM2 & $2 \mathrm{r} 2.5, \mathrm{C} 3$ & $4 \mathrm{~m} 1, \mathrm{C} 3$ & 4M1, C3 & $3 \mathrm{M} 1.5, \mathrm{C} 4$ & 4M1, D4 & 4R1.5, A4 & $4 \mathrm{R} 1.5, \mathrm{D} 4$ \\
\hline EM3 & $4 \mathrm{~m} 1, \mathrm{C} 3$ & $5 \mathrm{~m} 1, \mathrm{D} 4$ & $5 \mathrm{M} 1, \mathrm{D} 4$ & $4 \mathrm{R} 1.5, \mathrm{D} 4$ & $4 \mathrm{R} 2.5, \mathrm{~A} 4$ & $5 \mathrm{M} 1, \mathrm{C} 4$ & $5 \mathrm{M} 2, \mathrm{C} 4$ \\
\hline $\begin{array}{c}\text { Teeth with } \\
\text { Clear Bracket }\end{array}$ & $\begin{array}{c}\text { Post } \\
\text { placement }\end{array}$ & 24 Hours & 72 Hours & 1 Week & 2 Weeks & 3 Weeks & 4 Weeks \\
\hline WC1 & $5 \mathrm{~m} 2, \mathrm{C} 4$ & $5 \mathrm{~m} 2, \mathrm{C} 4$ & $5 \mathrm{~m} 2, \mathrm{C} 4$ & $5 \mathrm{~m} 2, \mathrm{C} 4$ & $5 \mathrm{~m} 2, \mathrm{C} 4$ & $5 \mathrm{~m} 2, \mathrm{C} 4$ & $5 \mathrm{~m} 2, \mathrm{C} 4$ \\
\hline WC2 & 4M3, A4 & $4 \mathrm{M} 3, \mathrm{~A} 4$ & $4 \mathrm{M} 3, \mathrm{~A} 4$ & $4 \mathrm{M} 3, \mathrm{~A} 4$ & $4 \mathrm{M} 3, \mathrm{~A} 4$ & 4M3, A4 & $4 \mathrm{M} 3, \mathrm{~A} 4$ \\
\hline WC3 & $3 \mathrm{M} 3, \mathrm{~A} 3.5$ & $3 \mathrm{M} 3, \mathrm{~A} 3.5$ & $3 \mathrm{M} 3, \mathrm{~A} 3.5$ & $3 \mathrm{M} 3, \mathrm{~A} 3.5$ & $3 \mathrm{M} 3, \mathrm{~A} 3.5$ & $3 \mathrm{M} 3, \mathrm{~A} 3.5$ & 3M3, A3.5 \\
\hline DrC1 & $3 \mathrm{~m} 3, \mathrm{~A} 3.5$ & $3 \mathrm{~m} 3, \mathrm{~A} 3.5$ & $4 \mathrm{M} 3, \mathrm{~A} 4$ & $4 \mathrm{M} 3, \mathrm{~A} 4$ & $4 \mathrm{M} 3, \mathrm{C} 4$ & $4 \mathrm{M} 3, \mathrm{C} 4$ & $4 \mathrm{M} 3, \mathrm{C} 4$ \\
\hline DrC2 & $4 \mathrm{~m} 3, \mathrm{~A} 4$ & $4 \mathrm{~m} 3, \mathrm{~A} 4$ & $5 \mathrm{M} 2, \mathrm{C} 4$ & $5 \mathrm{M} 3, \mathrm{C} 4$ & $5 \mathrm{M} 3, \mathrm{C} 4$ & $5 \mathrm{M} 3, \mathrm{C} 4$ & $5 \mathrm{M} 3, \mathrm{C} 4$ \\
\hline DrC3 & $3 \mathrm{~m} 3, \mathrm{~A} 3.5$ & $4 \mathrm{~m} 3, \mathrm{~A} 4$ & $4 \mathrm{M} 3, \mathrm{~A} 4$ & $4 \mathrm{M} 3, \mathrm{~A} 4$ & $5 \mathrm{M} 2, \mathrm{C} 4$ & $4 \mathrm{M} 3, \mathrm{C} 4$ & $4 \mathrm{M} 3, \mathrm{C} 4$ \\
\hline $\mathrm{CC} 1$ & $3 \mathrm{~m} 3, \mathrm{~A} 3.5$ & $4 \mathrm{~m} 3, \mathrm{~A} 4$ & $5 \mathrm{M} 2, \mathrm{C} 4$ & $5 \mathrm{M} 2, \mathrm{C} 4$ & $5 \mathrm{M} 3, \mathrm{C} 4$ & $5 \mathrm{M} 3, \mathrm{C} 4$ & $5 \mathrm{M} 3, \mathrm{C} 4$ \\
\hline $\mathrm{CC} 2$ & $4 \mathrm{~m} 3, \mathrm{~A} 4$ & $4 \mathrm{~m} 3, \mathrm{~A} 4$ & $5 \mathrm{M} 3, \mathrm{C} 4$ & $5 \mathrm{M} 3, \mathrm{C} 4$ & $5 \mathrm{M} 3, \mathrm{C} 4$ & $5 \mathrm{M} 3, \mathrm{C} 4$ & $5 \mathrm{M} 3, \mathrm{C} 4$ \\
\hline $\mathrm{CC} 3$ & $3 \mathrm{r} 1.5, \mathrm{C} 3$ & $5 \mathrm{~m} 1, \mathrm{C} 4$ & $4 \mathrm{M} 3, \mathrm{C} 4$ & $4 \mathrm{M} 3, \mathrm{C} 4$ & $5 \mathrm{M} 2, \mathrm{C} 4$ & $5 \mathrm{M} 2, \mathrm{C} 4$ & $5 \mathrm{M} 2, \mathrm{C} 4$ \\
\hline EC1 & $4 \mathrm{~m} 1, \mathrm{~A} 4$ & $4 \mathrm{~m} 2, \mathrm{~A} 4$ & $4 \mathrm{M} 2, \mathrm{~A} 4$ & $4 \mathrm{M} 3, \mathrm{~A} 4$ & $4 \mathrm{M} 3, \mathrm{~A} 4$ & $5 \mathrm{M} 2, \mathrm{C} 4$ & $5 \mathrm{M} 2, \mathrm{C} 4$ \\
\hline EC2 & $4 \mathrm{~m} 3, \mathrm{~A} 3.5$ & $4 \mathrm{~m} 3, \mathrm{~A} 3.5$ & $3 \mathrm{M} 3, \mathrm{~A} 3.5$ & 3M3, A3.5 & $4 \mathrm{M} 3, \mathrm{~A} 4$ & $4 \mathrm{M} 3, \mathrm{~A} 4$ & $4 \mathrm{M} 3, \mathrm{~A} 4$ \\
\hline EC3 & $2 \mathrm{~m} 3, \mathrm{~B} 3$ & $2 \mathrm{~m} 3, \mathrm{~B} 3$ & 2M3, B3 & $3 \mathrm{M} 3, \mathrm{~B} 4$ & $3 \mathrm{M} 3, \mathrm{~B} 4$ & $3 \mathrm{M} 3, \mathrm{~B} 4$ & $2 \mathrm{M} 3, \mathrm{~B} 4$ \\
\hline
\end{tabular}

${ }^{\star}$ WM: Metal bracket immersed in water; DrM: Dr. Pepper; CM: Coffee; EM: Red Bull; ${ }^{\star}$ WC: Clear bracket immersed in water; DrC: Dr. Pepper; CC: Coffee; EC: Red Bull. 
hours, seven days, 14 days, 21 days, and 28 days. After the final color data was collected, the roots of the samples were cut, and the coronal portion of the sample was mounted in acrylic resin, leaving the buccal side with bonded brackets exposed. The shear bond strength was recorded for each bracket using an Ultra Tester machine (Ultra Tester ${ }^{\mathrm{Tm}}$ Bond Strength Testing Machine) in MPa. The shear bond strength was analyzed using two-way ANOVA and post-hoc Tukey tests.

\section{Results}

The three dietary components had a variable change in the shade of the teeth for both metal and clear brackets after four weeks of immersion. Teeth immersed in Dr. Pepper and coffee, predictably, had the most significant eventual changes in color, measuring at the darkest classic Vita shade (C4) within 3 days $83.33 \%$ of the time (Table 1), with coffee samples exhibiting the quickest change. Red Bull, which has more value (lightness) than Dr. Pepper or coffee, presented less shade change over time. No significant changes in the shade were observed for teeth immersed in water over the 4 -week period (Table 1). Data extracted from shear bond strength testing is represented in Figure 1. Results showed that metal brackets had a lower shear bond strength compared to clear brackets, where the difference was statistically significant according to both two-way ANOVA ( $p=$ $0.036)$ and Tukey $(\mathrm{p}=0.015)$ analyses. The overall mean bond strength for the clear and metal brackets (21.68 $\mathrm{MPa}$ and $13.06 \mathrm{MPa}$, respectively) is reflective of previously described values in a similarly modeled study utilizing extracted premolars [15]. For each set (metal brackets and clear brackets), the dietary solutions appeared to follow a trend empirically, with coffee-soaked teeth exhibiting the lowest shear bond strength, followed by Dr. Pepper, then Red Bull; however, ANOVA analysis showed the differences between intra-bracket type samples (e.g. metal in coffee vs. metal in Red Bull) and between beverages as a whole (e.g. all brackets in coffee vs. all brackets in Red Bull) were insignificant ( $p>0.05)$.

\section{Discussion}

Clinically, the stability of orthodontic bracket bond strength and esthetics are of

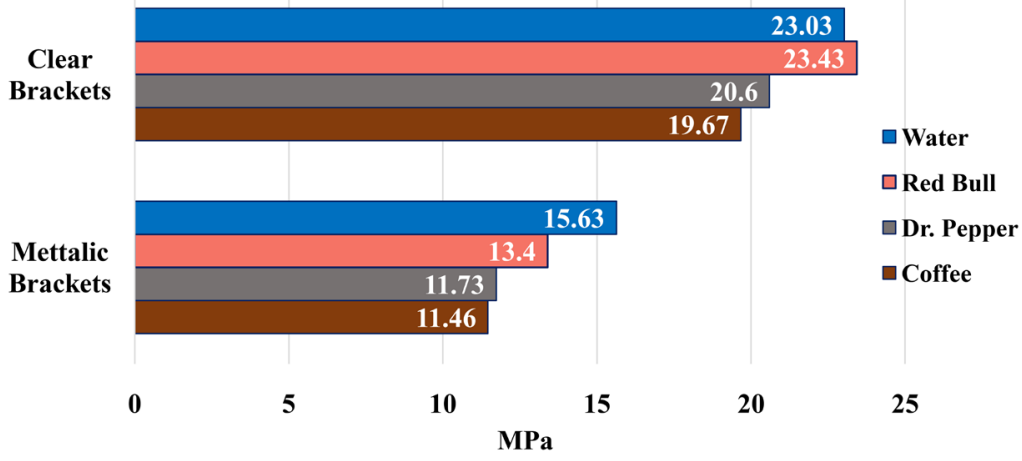

Figure 1. Mean shear bond strength (MPa) across all samples after 4 weeks of immersion. 
primary concern for both patients and practitioners. The present results showed that there are significant changes in the performance of different orthodontic brackets when exposed to acidic beverages. Impaired shear bond strength of orthodontic brackets and enamel color degradation are considered clinical shortcomings in the oral environment.

There are several causes of the discoloration of enamel. Dietary beverages and colored mouth rinses can cause external discoloration. Stains can be distinguished either visually or by using a colorimeter; however, human eye sensitivity in detecting small color differences is restricted, and the determination of visual color comparisons is subjective. For that reason, an electronic colorimeter was integral to our efforts by offering consistency and objectivity to observing changes over time measured. In the present investigation, teeth immersed in Dr. Pepper and coffee showed the most significant color changes. The current findings come into agreement with the investigation by Faltermeier et al., which showed that unsatisfactory color stability of the orthodontic adhesive system was noticed after 72 hours of exposure to pigmented dietary components such as tea [16]. Whether there was an influence from the adhesive or corrosion of the titanium brackets in this study remains unclear. For the purposes of this study, the exposure time was set to up to four weeks (28 days), as in a previous investigation it was noted that dental composite color difference was determined mainly after four weeks [17]. While composite was not a factor in our study, this timeline assisted in guiding our investigative framework. The results are in agreement with previous research which revealed that certain diet components, such as coffee, may cause severe staining of resin base esthetic restorative materials when compared with other dietary components [18] [19].

It has been concluded that acidic, low $\mathrm{pH}$ drinks provide a regular supply of corrosive agents for metallic orthodontic appliances and that the acidic environment will increase the corrosion susceptibility of certain metals, such as stainless steel and titanium brackets [5] [20] [21]. An in vivo study showed that the titanium and steel brackets undergo degradation in acidic conditions below $\mathrm{pH}$ 3.5. The consumption of low $\mathrm{pH}$ drinks can play role in reducing the oral environment $\mathrm{pH}$ which will influence sensitivity of metal brackets to the corrosive influence [21].

Material properties such as bond strength play some essential roles in the survivability of orthodontics brackets. Ceramic brackets bond to the tooth by forming chemical and mechanical bonds. The present shear bond strength results showed that metal brackets recorded the lowest shear bond strength. This finding comes into agreement with previous studies that reported that the mean SBS of ceramic brackets was superior when compared with that metallic brackets [15] [22]. This could be due to the corrosive influences of the dietary components and/or the erosive effect of the dietary component on enamel.

It is tempting to associate an overall trend with respect to the $\mathrm{pH}$ of each dietary solution; however, an additional factor to consider would be the effect of 
solution temperature in combination with $\mathrm{pH}$ on the enamel bond. According to our data, the clear brackets had a higher shear bond strength compared to metal brackets. It was surmised that this was due to the integration of the bonding material with the ceramic. The preparation of the ceramic surfaces leads to the formation of porosities and micro-pores, which increases the ceramic brackets' bond strength. Orthodontic brackets are continuously exposed to the oral environment and compounds that may affect their bonding integrity. While our results seemed to show evidence of a trend empirically, they were, in this regard, not significant for our sample size and further study is needed in this matter. As this investigation was conducted in an in vitro environment, further study also needs to be conducted with the consideration of oral health habits such as tooth brushing and the presence of fluoridated toothpaste that may have an impact on the outcome.

\section{Conclusion}

Within the limitations of this study, different acidic dietary components tend to affect the color stability of teeth with bonded brackets. Additionally, the clear orthodontic brackets had a statistically significant higher shear bond strength compared to metallic brackets after four weeks of immersion in the selected dietary components. Further study is needed to confirm the findings of this pilot study.

\section{Authors' Contributions}

NHA and TA conceived the protocol; NHA, TF and TA revised the manuscript; TF, SA, JL and NHA contributed to data acquisition and interpretation; JL performed the statistics. All authors read and approved the final version of the manuscript.

\section{Funding}

This research did not receive any specific grant from funding agencies in the public, commercial, or not-for-profit sectors.

\section{Ethics Approval and Consent to Participate}

No ethical approval was required for the study since the Institutional Research Board (IRB) of UNLV classified it as an exclusion review (laboratory research).

\section{Conflicts of Interest}

The authors declare no conflicts of interest regarding the publication of this paper.

\section{References}

[1] Işıksal, E., Hazar, S. and Akyalçın, S. (2006) Smile Esthetics: Perception and Comparison of Treated and Untreated Smiles. American Journal of Orthodontics and 
Dentofacial Orthopedics, 129, 8-16. https://doi.org/10.1016/j.ajodo.2005.07.004

[2] Al Maaitah, E.F., Omar, A.A. and Al-Khateeb, S.N. (2013) Effect of Fixed Orthodontic Appliances Bonded with Different Etching Techniques on Tooth Color: A Prospective Clinical Study. American Journal of Orthodontics and Dentofacial Orthopedics, 144, 43-49. https://doi.org/10.1016/j.ajodo.2013.02.020

[3] Telang, A., Narayana, I.H., Madhu, K.S., Kalasaiah, D., Ramesh, P. and Nagaraja, S. (2018) Effect of Staining and Bleaching on Color Stability and Surface Roughness of Three Resin Composites: An in Vitro Study. Contemporary Clinical Dentistry, 9 , 452.

[4] Sari, M.E., Erturk, A.G., Koyuturk, A.E. and Bekdemir, Y. (2014) Evaluation of the Effect of Food and Beverages on Enamel and Restorative Materials by SEM and Fourier Transform Infrared Spectroscopy. Microscopy Research and Technique, 77, 79-90. https://doi.org/10.1002/jemt.22315

[5] House, K., Sernetz, F., Dymock, D., Sandy, J.R. and Ireland, A.J. (2008) Corrosion of Orthodontic Appliances-Should We Care? American Journal of Orthodontics and Dentofacial Orthopedics, 133, 584-592. https://doi.org/10.1016/j.ajodo.2007.03.021

[6] Abu-bakr, N., Han, L., Okamoto, A. and Iwaku, M. (2000) Color Stability of Compomer after Immersion in Various Media. The Journal of Esthetic and Restorative Dentistry, 12, 258-263. https://doi.org/10.1111/j.1708-8240.2000.tb00232.x

[7] Arthur, S., Frederick, C., John, C. and Tak, W. (2004) Color Stability of Provisional Prosthodontic Materials. Journal of Prosthetic Dentistry, 91, 447-452. https://doi.org/10.1016/j.prosdent.2004.03.005

[8] Stober, T., Gilde, H. and Lenz, P. (2001) Color Stability of Highly Filled Composite Resin Materials for Facings. Dental Materials, 17, 87-94.

https://doi.org/10.1016/S0109-5641(00)00065-8

[9] Navarro, R., Vicente, A., Ortiz, A.J. and Bravo, L.A. (2010) The Effects of Two Soft Drinks on Bond Strength, Bracket Microleakage, and Adhesive Remnant on Intact and Sealed Enamel. European Journal of Orthodontics, 33, 60-65. https://doi.org/10.1093/ejo/cjq018

[10] Silva, T.M., Sales, A.L., Pucci, C.R., Borges, A.B. and Torres, C.R. (2017) The Combined Effect of Food-Simulating Solutions, Brushing and Staining on Color Stability of Composite Resins. Acta Biomaterialia Odontologica Scandinavica, 3, 1-7. https://doi.org/10.1080/23337931.2016.1276838

[11] Oncag, G., Tuncer, A. and Tosun, Y. (2005) Acidic Soft Drinks Effects on the Shear Bond Strength of Orthodontic Brackets and a Scanning Electron Microscopy Evaluation of the Enamel. The Angle Orthodontist, 75, 247-253.

[12] Reddy, A., Norris, D.F., Momeni, S.S., Waldo, B. and Ruby, J.D. (2016) The $\mathrm{pH}$ of Beverages in the United States. Journal of the American Dental Association, 147, 255-263. https://doi.org/10.1016/j.adaj.2015.10.019

[13] Las Vegas Valley Water District. https://www.lvvwd.com/water-quality/reports/summary-las-vegas-valley.html

[14] Pytko-Polonczyk, J., Jakubik, A., Przeklasa-Bierowiec, A. and Muszynska, B. (2017) Artificial Saliva and Its Use in Biological Experiments. Journal of Physiology and Pharmacology, 68, 807-813.

[15] Reddy, Y.G., Sharma, R., Singh, A., Agrawal, V. and Chaturvedi, S. (2013) The Shear Bond Strengths of Metal and Ceramic Brackets: An In-Vitro Comparative Study. Journal of Clinical and Diagnostic Research, 7, 1495-1497.

https://doi.org/10.7860/JCDR/2013/5435.3172 
[16] Faltermeier, A., Rosentritt, M., Reicheneder, C. and Behr, M. (2008) Discolouration of Orthodontic Adhesives Caused by Food Dyes and Ultraviolet Light. European Journal of Orthodontics, 30, 89-93. https://doi.org/10.1093/ejo/cjm058

[17] Ardu, S., Duc, O., Di Bella, E., Krejci, I. and Daher, R. (2018) Color Stability of Different Composite Resins after Polishing. Odontology, 106, 328-333.

https://doi.org/10.1007/s10266-017-0337-y

[18] Poggio, C., Ceci, M., Beltrami, R., Mirando, M., Wassim, J. and Colombo, M. (2016) Color Stability of Esthetic Restorative Materials: A Spectrophotometric Analysis. Acta Biomaterialia Odontologica Scandinavica, 2, 95-101. https://doi.org/10.1080/23337931.2016.1217416

[19] Barutcigil, Ç. and Yıldı, M. (2012) Intrinsic and Extrinsic Discoloration of Dimethacrylate and Silorane Based Composites. Journal of Dentistry, 40, e57-e63.

https://doi.org/10.1016/j.jdent.2011.12.017

[20] Schiff, N., Dalard, F., Lissac, M., Morgon, L. and Grosgogeat, B. (2005) Corrosion Resistance of Three Orthodontic Brackets: A Comparative Study of Three Fluoride Mouthwashes. European Journal of Orthodontics, 27, 541-549.

https://doi.org/10.1093/ejo/cji050

[21] Harzer, W., Schröter, A., Gedrange, T. and Muschter, F. (2001) Sensitivity of Titanium Brackets to the Corrosive Influence of Fluoride-Containing Toothpaste and Tea. The Angle Orthodontist, 71, 318-323.

[22] Eslamian, L., Borzabadi-Farahani, A., Mousavi, N. and Ghasemi, A. (2012) A Comparative Study of Shear Bond Strength between Metal \& Ceramic Brackets \& Artificially Aged Composite Restoration Using Different Surface Treatments. European Journal of Orthodontics, 34, 610-617. https://doi.org/10.1093/ejo/cjr044

\section{Abbreviations}

ANOVA: Analysis of variance; SBS: Shear bond strength. 